\title{
A INSTITUCIONALIZAÇÃO DO GOVERNO ELETRÔNICO NO BRASIL
}

\section{RESUMO}

O artigo tem como objetivo identificar o estágio de institucionalização do governo eletrônico no Brasil e os possíveis reflexos dessa política na inclusão digital. A pesquisa realizada, de natureza qualitativa, baseou-se na opinião de informantes-chaves dos principais setores institucionais que compõem o e-gov no país: setor público, iniciativa privada, terceiro setor e academia. A análise de conteúdo foi o método utilizado para se extrair a percepção dos entrevistados sobre a política de e-gov, tendo sido utilizado o software Atlas.ti para auxiliar na ordenação conceitual dos dados coletados. Concluiu-se que o único aspecto que poderia ser considerado institucionalizado no governo eletrônico seria a relação do Estado com o terceiro setor na política de inclusão digital, encontrando-se os demais aspectos investigados, em sua maioria, em estágios de semi-institucionalização.

\section{Paulo Henrique Ramos Medeiros \\ Tribunal de Contas da União \\ Tomás de Aquino Guimarães \\ UnB}

\begin{abstract}
This study attempts to identify the institutionalization stage of the electronic government in Brazil and the possible implications of this policy for the digital divide. A qualitative research was undertaken based on the opinion of key informers from the sectors that constitute the e-gov in the country: public sector, private sector, third sector and academy. Content analysis was used to verify the interviewees perceptions about the e-gov policy, using the Atlas.ti software to help with conceptual ordering of collected data. Results show that the only aspect that could be viewed as institutionalized in the e-government would be the relation between the State and the third sector in the digital divide policy. The other aspects, in its majority, would be in semi-institutionalized stages.
\end{abstract}

PALAVRAS-CHAVE Governo eletrônico, inclusão digital, Internet, institucionalização, teoria institucional. KEYWORDS Electronic government, digital divide, Internet, institutionalization, institutional theory. 


\section{INTRODUÇÃO}

Os governos de distintos países operam num mundo complexo, precisando se adaptar às novas realidades, como a globalização e a era do conhecimento, na qual se molda a sociedade da informação, contexto em que as tecnologias de informação e comunicação (TIC) têm papel crucial no modo como o Estado cumpre suas principais funções. Essas tecnologias mudam a abordagem da gestão pública, devendo-se levar em conta que cidadãos, empresas e demais organizações querem ter acesso ao governo de modo cada vez mais rápido e facilitado, na expectativa de que os programas governamentais estejam focados em suas necessidades.

A Internet, como veículo de aproximação do Estado com o cidadão, é o principal instrumento para tornar o governo cada vez mais "eletrônico". A presença governamental na Internet visa tornar o aparato administrativo menos aparente de forma presencial, mas, ao mesmo tempo, mais próximo do cidadão e mais eficiente na realização de seus objetivos, com a utilização de técnicas e sistemas de informática e comunicações.

Esses supostos benefícios do governo eletrônico só têm sentido, entretanto, se o público-alvo de suas ações tiver condições de acesso à Internet e capacitação para usufruir das informações e serviços ofertados pelo poder público. No Brasil, onde as desigualdades sociais são grandes, a infra-estrutura de telecomunicações ainda não alcança de modo igualitário todo o território nacional. O nível de educação da população é baixo, e corre-se o risco de as possíveis vantagens do e-gov ficarem restritas a uma pequena parcela da população, razão pela qual ganham importância as ações de inclusão digital, que visam proporcionar o acesso à Internet, de modo indistinto, a todos os cidadãos.

O presente artigo tem como objetivo identificar o estágio de institucionalização do governo eletrônico no Brasil, nos aspectos de formulação da política, estrutura legal e relações entre os atores institucionais envolvidos, além dos possíveis reflexos dessa política para a inclusão digital. Considera como seu principal alicerce teórico a perspectiva institucional, servindo como fator preponderante para se conhecer o ambiente institucional no qual o tema se insere. Como ressaltam Machado-da-Silva et al. (2003, p. 179), "a inserção da perspectiva institucional de análise no campo dos estudos organizacionais é crescente, em termos quantitativos e qualitativos". Este trabalho contribui para a aplicação dessa teoria a uma pesquisa empírica.

\section{GOVERNO ELETRÔNICO E INCLUSÃO DIGITAL}

$\mathrm{O}$ advento da Internet e as inovações tecnológicas em comunicações proporcionaram às organizações a possibilidade de migrar seus sistemas existentes em plataformas convencionais para sistemas com interface web. O esgotamento da sobrevida de sistemas legados pode ser considerado ainda um exemplo de fator que motivou a construção de sistemas baseados na Internet, os quais conformam, na prática, o governo eletrônico. Outros aspectos que incentivaram o surgimento dessa inovação foram, em ordem de relevância para os governos: (1) a necessidade de as administrações aumentarem sua arrecadação e melhorar seus processos internos, e (2) as pressões da sociedade para que o governo otimize seus gastos e atue, cada vez mais, com transparência, qualidade e de modo universal na oferta de serviços aos cidadãos e organizações em geral.

As possibilidades de otimização de processos de governo baseados em soluções de TIC, ou mesmo a criação de novos processos, passam por princípios definidos pelos conceitos de governo eletrônico. Para as Nações Unidas (2002, p. 1), o e-governo é definido como a "utilização da Internet e da web para ofertar informações e serviços governamentais aos cidadãos", enquanto Okot-Uma (2001, p. 9) afirma que a expressão "refere-se a processos e estruturas relativos ao fornecimento eletrônico de serviços governamentais ao público".

Ferguson (2002, p. 104-105) prefere uma definição de governo eletrônico um pouco mais ampla, envolvendo o conceito de governança eletrônica - que incorpora a democracia eletrônica - e o de prestação eletrônica de serviços voltada para "a garantia e a prestação de serviços do governo por meios eletrônicos".

Para os fins deste artigo, o governo eletrônico é visto como a prestação de informações e a disponibilização de serviços governamentais por meio da Internet. Esta definição distingue-se do conceito de governança eletrônica, que é utilizado por alguns autores de modo indistinto para as definições de e-gov e e-governança, ou, de modo mais específico, como sendo esse construto a dimensão política mais avançada daquele (Ruediger, 2002).

No entanto, reconhece-se que essa é uma distinção apenas didática, visto que ambos os construtos se conformam a partir de processos organizacionais, políticos e institucionais que visam à construção de novos mecanismos de governança, com o emprego das tecnologias de informação e comunicação, cujos resultados ainda não podem ser previstos com exatidão (Fountain, 2001).

No Brasil, os projetos de e-gov dos demais entes federa- 
tivos têm sido estimulados pelo progresso das iniciativas do governo federal, desenvolvidas em duas vertentes de atuação, que por vezes se sobrepõem: (1) nas diretrizes do Comitê Executivo do Governo Eletrônico, executadas por meio do Programa Governo Eletrônico (Brasil, 2000a) e, eventualmente, de outros programas governamentais, e (2) em três das sete linhas de ação do Programa Sociedade da Informação - "Universalização de Serviços para a Cidadania", "Governo ao Alcance de Todos" e "Infra-estrutura Avançada e Novos Serviços" (Brasil, 2000b).

Com a criação do Comitê Executivo do Governo Eletrônico (CEGE), em outubro de 2000, foram definidos papéis a serem cumpridos por diversos órgãos públicos e implementadas ações e normas que conformaram o ambiente institucional no qual o e-gov se estabeleceu no país. Em 2003 foram criados oito comitês técnicos no âmbito do CEGE, com a finalidade de coordenar e articular o planejamento e a implementação de projetos e ações nas respectivas áreas de competência.

As disparidades sociais existentes no Brasil e a ênfase crescente na implementação de políticas de cunho social motivam a abordagem do conceito de inclusão digital. Embora o e-gov apresente, em princípio, diversas vantagens, deve-se levar em conta a existência da exclusão digital - ou "divisão digital" -, que diz respeito à desigualdade de acesso à Internet. A expressão pode ser definida como a falha no provimento, pelos governos, de acesso universal a serviços de informação e comunicação, indistintamente a todos os cidadãos, ou seja, o "provimento assimétrico na sociedade de instrumentos de acesso a serviços na web" (Ruediger, 2003, p. 4).

Essa vem sendo uma preocupação dos governos ao serem implementados projetos de e-gov pela necessidade de se combaterem as diferenças entre os que possuem e os que não possuem acesso à Internet com ações de inclusão digital. Esse tipo de abordagem, especialmente num país como o Brasil, notoriamente desigual em distribuição de renda e acesso a novas tecnologias, é vital para os projetos de governo eletrônico. Ademais, as TIC têm o potencial de aumentar essas diferenças, ao "isolar indivíduos, ao prover um melhor acesso à informação apenas para os bem educados, tecnologicamente bem equipados, bem organizados e para aqueles com recursos" (Kakabadse, Kakabadse e Kouzmin, 2003, p. 52).

No caso de países em desenvolvimento, "a realidade socioeconômica exige que as políticas de implantação de sistemas de governo eletrônico devam estar casadas com aquelas que contribuam para o combate à exclusão digital" (Diniz, 2002, p. 6). Silveira (2001, p. 41) reforça esse entendimento alertando que "seria completamente injusto e pouco eficaz organizar o governo eletrônico sem, paralelamente, buscar a inserção na sociedade em rede das camadas excluídas da população".

\section{ABORDAGEM INSTITUCIONAL}

A teoria institucional tem suas raízes nos trabalhos de Peter Selznick, no final dos anos 1940, sendo o autor considerado o precursor dessa abordagem por "introduzir as bases de um modelo institucional e interpretar as organizações como uma 'expressão estrutural da ação racional' que, ao longo do tempo, são sujeitas às pressões do ambiente social e transformam-se em sistemas orgânicos" (Carvalho e Vieira, 2003, p. 23). Essa perspectiva, segundo esses autores, recebeu uma contribuição especial da sociologia do conhecimento desenvolvida por Berger e Luckmann (1966), com o chamado construtivismo social. Essa vertente de cunho sociológico tem seu ponto de partida teórico na noção de instituição como o produto final da institucionalização, definida esta como a "tipificação recíproca de ações habituadas por tipos de atores" (Berger e Luckmann, 1966, p. 72).

Carvalho e Vieira (2003) repassam a teoria institucional nas suas vertentes política, econômica e sociológica, enfocando as bases históricas da teoria e os textos clássicos que iniciaram uma ruptura com o "velho institucionalismo" e que deram lugar a uma abordagem com maior poder explicativo da realidade organizacional denominada, segundo esses autores, de novo institucionalismo. Essa abordagem é resultante da progressão dos estudos acerca da teoria institucional, tendo contribuído para novos significados e entendimentos (Powell e DiMaggio, 1991).

Meyer, Boli e Thomas (1994, p. 10) argumentam que os termos instituição e institucionalização "têm significados vagos e variáveis nas discussões sociológicas modernas". Esse ponto de vista é reforçado por Tolbert e Zucker (1997, p. 175) ao afirmarem que haveria "pouco consenso na definição de conceitos-chaves, medidas e métodos nessa tradição teórica [a teoria institucional]". Tais conceitos seriam referentes a macropadrões da estrutura social e atividades em torno de regras gerais, mas com um alto grau de incerteza sobre a natureza de tais regras. Meyer, Boli e Thomas (1994, p. 10) propõem, para dar um maior direcionamento à discussão, as seguintes definições:

Instituições: regras culturais que dão significado e valor coletivos a entidades particulares e atividades, integrando-as a um contexto maior. Vemos ambos, padrões de atividade e as unidades envolvidas neles (indivíduos e 
outras entidades sociais), como construídas por essas regras mais amplas.

Institucionalização: é o processo por meio do qual um dado número de unidades e um padrão de atividades são mantidos de modo normativo e cognitivo em seus lugares, e praticamente assumidos como legítimos (seja a partir de uma lei formal, costume ou conhecimento).

Scott (1994), por sua vez, propõe uma definição mais complexa de instituições, como um "modelo em camadas" (veja Figura 1), sendo tais camadas compostas por (1) sistemas de significação e padrões relacionados de comportamento, que contêm (2) elementos simbólicos, inclusive componentes representativos, constitutivos e normativos, que são (3) constringidos por processos reguladores. A partir desse modelo, Scott (2001) propõe que as instituições sejam visualizadas por meio de três pilares, que se identificam com as camadas citadas: (1) culturalcognitivo; (2) normativo e (3) regulador.

A partir do modelo apresentado na Figura 1, Scott (1994, p. 68) sintetiza a seguinte definição: "instituições são sistemas simbólicos e de comportamento que contêm regras representativas, constitutivas e normativas, juntamente com mecanismos reguladores que definem um sistema de significado comum e que dão origem a diferentes atores e rotinas de ação". Instituições seriam, em decorrência dessa definição, "estruturas sociais multifacetadas e duráveis, feitas de elementos simbólicos, atividades sociais e recursos materiais" (Scott, 2001, p. 49).

Machado-da-Silva et al. (2003) apresentam uma adaptação desse modelo ao contexto do Brasil - intitulado "modelo de criação e difusão institucional" - no qual é enfatizado o pilar regulador, tendo em vista o formalismo, que atua no país como mecanismo institucional coercitivo de mudança social. O "formalismo" é definido por Machado-da-Silva et al. (2003, p. 188) como a "discrepância entre as normas prescritas legalmente e as atitudes concretas adotadas quando de sua real implementação". Esses autores esclarecem, ainda, que o formalismo estaria associado aos três pilares institucionais e legitimaria, na sociedade brasileira, "o mecanismo institucional coercitivo como instrumento de manutenção da ordem e, paradoxalmente, de transformação social" (Machado-da-Silva et al., 2003, p. 191).

A institucionalização é vista por Tolbert e Zucker (1997) como um conjunto de processos seqüenciais - habitualização, objetificação e sedimentação - que sugerem variabilidade nos níveis de institucionalização. O primeiro desses processos, a habitualização, envolveria a geração de novos arranjos estruturais em resposta a pro-

Figura 1 - Instituições: modelo em camadas

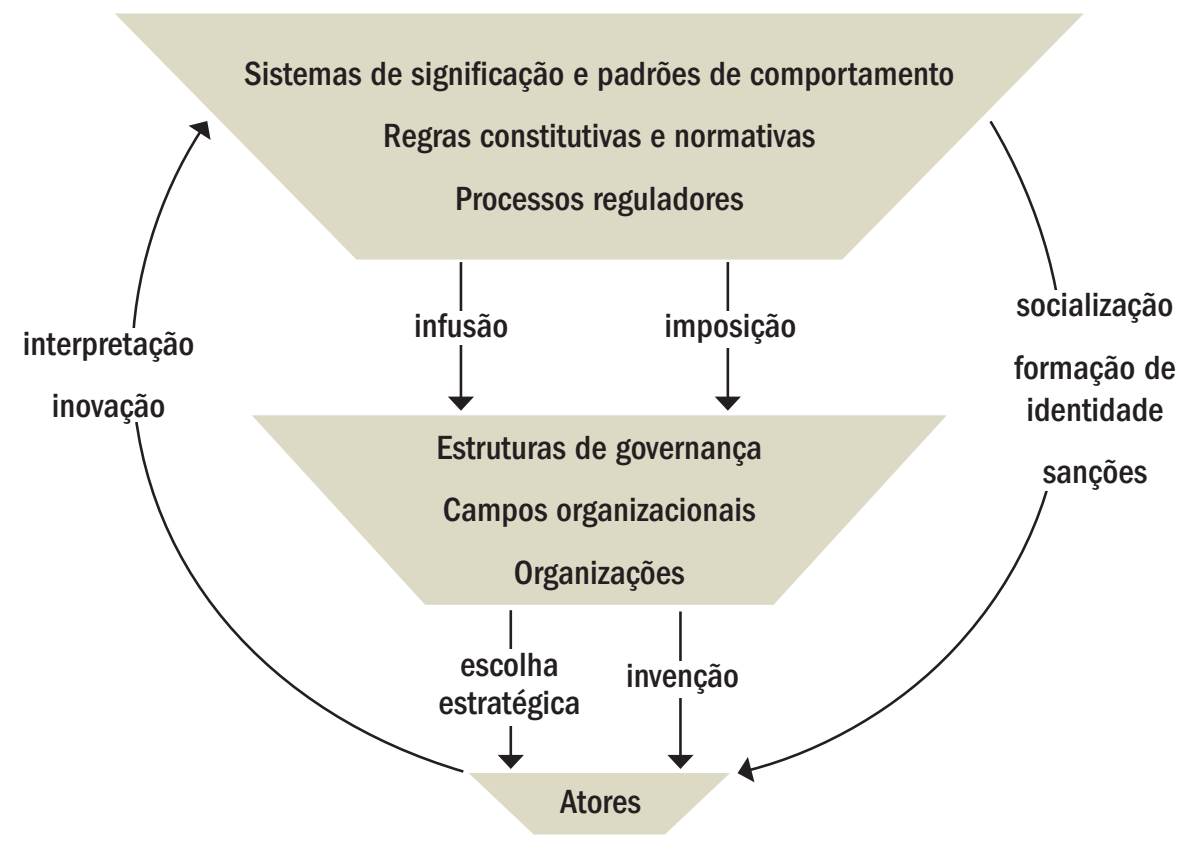

Fonte: Scott (1994, p. 57). 
blemas ou conjuntos de problemas organizacionais específicos, como também a formalização de tais arranjos em políticas e procedimentos de uma dada organização ou um conjunto de organizações que encontrem problemas iguais ou semelhantes. A objetificação envolveria o desenvolvimento de certo grau de consenso social entre os decisores da organização a respeito do valor da estrutura e sua crescente adoção pelas organizações com base nesse consenso. A sedimentação, por sua vez, seria um processo que se apóia na continuidade histórica da estrutura e, especialmente, em sua sobrevivência pelas várias gerações de membros da organização.

Os estágios da institucionalização propostos por Tolbert e Zucker (1997) são, dependendo do estado em que os processos se encontram, os seguintes: (1) estágio pré-institucional - processos habitualizados; (2) estágio semi-institucional - processos objetificados; e (3) estágio de total institucionalização - processos sedimentados. Embora os estágios pareçam, à primeira vista, seguir uma lógica seqüencial, vale ressalvar que existe a possibilidade de que os processos que os compõem obedeçam, na verdade, a uma trajetória circular em espiral. Assim, os distintos tipos de processos - habitualizados, objetificados e sedimentados - aconteceriam simultaneamente e se reiniciariam por diversas vezes durante o processo de institucionalização, mas não da mesma maneira como ocorreram na trajetória original.

A explicação para essa trajetória distinta daquela proposta por Tolbert e Zucker (1997) - como sendo o grau de institucionalização uma seqüência linear de eventos ordenados temporalmente - residiria no fato de que os três tipos de processos existiriam no mundo real em momentos simultâneos. Dessa maneira, a sociedade e cada uma de suas partes seriam simultaneamente caracterizadas por esses três momentos do processo de institucionalização (Berger e Luckmann, 1966).

Outras observações importantes para situar esta pesquisa em relação à sua base institucional é a ênfase a ser dada em relação ao (1) nível de análise (Machado-daSilva e Gonçalves, 1998; Scott, 2001) e ao (2) contexto institucional de referência (Machado-da-Silva, Fonseca e Fernandes, 2000).

Scott (2001) define os níveis de análise em seis categorias, variando do macro para o micro: (1) sistema mundial, (2) sociedade, (3) campo organizacional, (4) população organizacional, (5) organização e (6) subsistema organizacional. Estabeleceu-se para esta pesquisa o nível de sociedade seguindo o conceito de setor societário apresentado por Scott e Meyer (1991). Cabe ressaltar que os setores societários são caracterizados funcionalmente
(Scott e Meyer, 1991) e não por abrangência geográfica, como os campos organizacionais (Scott, 1998).

O contexto nacional conforma o segundo aspecto anteriormente mencionado, relativo ao contexto institucional de referência, que, segundo destacam Machado-da-Silva e Gonçalves (1998, p. 226), traz à tona a distinção analítica entre ambientes técnicos e institucionais em diferentes níveis de análise - que podem considerar os contextos local, regional, nacional ou internacional -, enriquecendo "sobremaneira a abordagem da dinâmica de transformação organizacional".

Na conformação de um determinado setor societário interessa saber, por exemplo, como sua lógica pode ser descrita, ou seja, como os processos institucionais ocorrem e quais são seus padrões de desenvolvimento. A lógica institucional refere-se, segundo Scott (2001, p. 39), "aos sistemas de crenças e práticas relacionadas que predominam em um campo organizacional".

A fim de explicar a estruturação de setores societários, Scott (2001, p. 202) propõe oito dimensões que auxiliam na descrição de sua lógica institucional, por facilitarem a investigação de processos de mudança institucional. Cinco dessas oito dimensões, a seguir apresentadas, foram utilizadas na interpretação e discussão dos resultados da pesquisa (precedidas por um asterisco):

a) * centralização de recursos: extensão onde os recursos financeiros empregados pelos atores do setor são concentrados;

b) * unidade de governança: extensão onde as estruturas de governança são congruentes na jurisdição e consistentes no sistema de regras enunciado e imposto;

c) * modo de governança público-privado: extensão onde as autoridades públicas versus privadas exercem controle sobre o setor;

d) isomorfismo estrutural: extensão onde os atores organizacionais do setor conformam-se a um único arquétipo ou modelo estrutural;

e) coerência nos limites organizacionais: extensão onde as formas organizacionais do setor exibem limites claros e bem demarcados;

f) * consenso na lógica institucional: extensão onde os atores no setor seguem e aderem às mesmas crenças gerais e modelos de ação ao executarem as atividades do setor;

g) * ligações organizacionais: extensão onde há um número relativamente grande de conexões formais e informais entre os atores organizacionais no setor;

h) clareza dos limites do setor: extensão onde existe insulamento relativamente alto e separação entre os atores e as estruturas do setor em relação a setores vizinhos. 


\section{MÉTODOS E PROCEDIMENTOS DE PESQUISA}

O presente estudo se caracteriza, quanto ao nível de investigação empírica, como descritivo. A partir da descrição das iniciativas que compõem as ações do governo eletrônico no Brasil, torna-se possível analisar o contexto institucional no qual a política se desenvolve.

A pesquisa englobou o período de 2000 a 2003, tendo em vista que "a formulação de uma política de tecnologia da informação e comunicação voltada para a administração pública [no Brasil] teve seu marco inicial na elaboração de documento que definiu diretrizes, objetivos e metas até 2003" (Brasil, 2002, p. 1), intitulado "Proposta de política de governo eletrônico para o Poder Executivo federal" (Brasil, 2000a), que foi lançado em setembro de 2000. Além disso, vale citar que o Comitê Executivo do Governo Eletrônico (CEGE) foi criado em outubro desse mesmo ano. O estudo foi delimitado às ações de governo eletrônico do Poder Executivo, no nível federal de governo, definidas e implementadas por meio do CEGE.

Foram realizadas as seguintes etapas e métodos de pesquisa. Bibliográfica: revisão da literatura em livros, periódicos, dissertações de mestrado e teses de doutorado, anais de congressos científicos e outras publicações; documental: documentos gerados pelo CEGE, Livro Verde do Programa Sociedade da Informação (Brasil, 2000b), Orçamentos da União no período de 2000 a 2003 e Plano Plurianual 20002003; de campo: coleta de dados primários por meio de entrevistas semi-estruturadas; pesquisa em instrumentos, ações e medidas tomadas pelo governo federal: formulação de políticas e ações de governo eletrônico a cargo do CEGE, iniciativas planejadas e executadas no governo federal em termos de governo eletrônico, observação de portais do governo brasileiro na Internet.

Os stakeholders entrevistados foram agrupados nos seguintes tipos, identificados neste artigo como "agentes [ou atores] institucionais" do ambiente do governo eletrônico: (1) gestores públicos (setor público), (2) empresários e consultores (iniciativa privada), (3) dirigentes de ONGs (terceiro setor) e (4) professores universitários (setor acadêmico). A seleção dos entrevistados foi feita a partir da análise das atribuições de seus cargos - no nível estratégico ou gerencial - e de seu grau de interação/ atuação em relação às ações do Poder Executivo federal relacionadas ao e-gov.

O Quadro 1 apresenta os entrevistados por setor institucional, tendo em vista os quatro diferentes roteiros de entrevista empregados na coleta dos dados, indicando as organizações abrangidas e o número de entrevistas realizadas em cada uma delas.
Para a coleta de dados foram utilizados roteiros de entrevistas semi-estruturadas para um único respondente por vez - entrevistas em profundidade -, com perguntas abertas. Foram entrevistadas 27 pessoas, no período de setembro a dezembro de 2003, variando a duração das entrevistas de 34 minutos (mínimo) a 2 horas e 16 minutos (máximo), num total de 32,5 horas de gravação e tempo médio de duração de 1 hora e 12 minutos.

A técnica utilizada para analisar os dados primários foi a análise de conteúdo, definida por Richardson et al. (1985) como um conjunto de técnicas para análise de comunicações, visando obter a descrição do conteúdo de mensagens. Vala (1986, p. 104) observa que a análise de conteúdo permite inferências sobre a fonte e a situação em que esta produziu o material objeto de análise, tendo como finalidade "efetuar inferências, com base numa lógica explicitada, sobre as mensagens cujas características foram inventariadas e sistematizadas".

Richardson et al. (1985) explicam que a análise de conteúdo constitui um conjunto de instrumentos metodológicos com as características de objetividade, sistematização e inferência. A objetividade se refere à "explicitação das regras e dos procedimentos utilizados em cada etapa da análise" (Richardson et al., 1985, p. 176). A sistematização, por sua vez, refere-se à "inclusão ou exclusão do conteúdo ou categorias de um texto de acordo com regras consistentes e sistemáticas" (Richardson et al., 1985, p. 177). Já a inferência refere-se à "operação pela qual se aceita uma proposição em virtude de sua relação com outras proposições já aceitas como verdadeiras" (Richardson et al., 1985, p. 177).

As características de objetividade, sistematização e inferência, citadas por Richardson et al. (1985), são detalhadas por Vala (1986), que menciona os seguintes tipos de operações mínimas para a prática da análise de conteúdo: (a) delimitação dos objetivos e definição de um quadro de referência teórico-orientador da pesquisa; (b) constituição de um corpus; (c) definição de categorias; (d) definição de unidades de análise; (e) quantificação (opcional).

Deve-se esclarecer que o corpus desta pesquisa foi constituído pelo conteúdo das entrevistas, ao qual foram agregadas, para compor as linhas convergentes de investigação, outras fontes de evidência, a exemplo dos documentos oficiais. A definição de categorias foi feita com base no referencial teórico e no trabalho exploratório sobre o corpus, conforme prevê Vala (1986). Nesse caso, como ocorreu na presente pesquisa, "as referências teóricas do investigador orientam a primeira exploração do material, mas este, por sua vez, pode contribuir para a reformulação ou alargamento das hipóteses e das problemáticas a estudar" (Vala, 1986, p. 112). 
A partir da categorização, foram efetivados os procedimentos previstos nas letras (d) e (e) anteriormente citadas, sendo as unidades de análise as citações selecionadas nas transcrições das entrevistas e a quantificação representada pelo grau de fundamentação e de densidade dos códigos identificados a partir dessas citações. O tipo de análise de conteúdo utilizada foi, portanto, a análise por categoria (Richardson et al., 1985; Vala, 1986), que se baseia na decodificação de um texto em diversos elementos, os quais são classificados e formam agrupamentos analógicos (resultado da codificação).
Devido à grande quantidade de dados e à complexidade das interações de opiniões dos quatro diferentes grupos de entrevistados, foi utilizado, para auxílio à análise de conteúdo e à ordenação conceitual, o software Atlas.ti, apropriado para a análise qualitativa de dados e informações.

Foram definidas, por meio de revisão bibliográfica, as seguintes variáveis para operacionalizar a pesquisa (categorização): (1) Formulação/Integração de Políticas; (2) Relações Institucionais e (3) Estrutura Legal. Para cada variável foram definidos códigos (unidades de análise)

Quadro 1 - Relação de entrevistados por setor institucional

\begin{tabular}{|c|c|c|}
\hline SETOR INSTITUCIONAL & ORGANIZAÇÃO & $\begin{array}{l}\text { TOTAL DE ENTREVISTA- } \\
\text { DOS POR ORGANIZAÇÃO }\end{array}$ \\
\hline \multirow{6}{*}{ SETOR PÚBLICO } & Instituto Nacional de Tecnologia da Informação (ITI) & 1 \\
\hline & $\begin{array}{l}\text { Programa Governo Eletrônico - Serviço de Atendimento ao Cidadão (Gesac) } \\
\text { - Ministério das Comunicações }\end{array}$ & 1 \\
\hline & Programa Sociedade da Informação - Ministério da Ciência e Tecnologia & 1 \\
\hline & $\begin{array}{l}\text { Secretaria de Logística e Tecnologia da Informação - Ministério do } \\
\text { Planejamento, Orçamento e Gestão (SLTI/MPOG) }\end{array}$ & 6 \\
\hline & Serviço Federal de Processamento de Dados (Serpro) & 1 \\
\hline & Tribunal de Contas da União (TCU) & 2 \\
\hline & TOTAL & 12 \\
\hline \multirow{4}{*}{ INICIATIVA PRIVADA } & Accenture & 2 \\
\hline & Cisco Brasil & 1 \\
\hline & Conectiva & 1 \\
\hline & Politec & 1 \\
\hline & TOTAL & 5 \\
\hline \multirow{6}{*}{ TERCEIRO SETOR } & Agência Eletrônica & 1 \\
\hline & $\begin{array}{l}\text { Comitê para Democratização da Informática do Distrito Federal e Entorno } \\
\text { (CDI-DF) }\end{array}$ & 1 \\
\hline & $\begin{array}{l}\text { Escola do Futuro - Centro de Inclusão Digital e Educação Comunitária } \\
\text { (Cidec) - Universidade de São Paulo (USP) }\end{array}$ & 1 \\
\hline & $\begin{array}{l}\text { Instituto Euvaldo Lodi (IEL) - Federação das Indústrias do Estado do Rio de } \\
\text { Janeiro (Firjan) }\end{array}$ & 1 \\
\hline & Projeto Sampa.Org & 1 \\
\hline & Rede de Informações para o Terceiro Setor (RITS) & 1 \\
\hline & 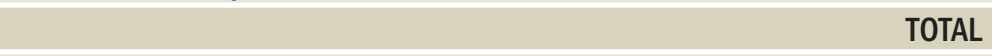 & 6 \\
\hline \multirow{4}{*}{ SETOR ACADÊMICO } & $\begin{array}{l}\text { Escola Brasileira de Administração Pública e de Empresas da Fundação Ge- } \\
\text { túlio Vargas (Ebape/FGV) }\end{array}$ & 1 \\
\hline & $\begin{array}{l}\text { Programa das Nações Unidas para o Desenvolvimento (PNUD) } \\
\text { London School of Economics and Political Science (LSE) }\end{array}$ & 1 \\
\hline & Universidade de São Paulo (USP) & 1 \\
\hline & Universidade do Estado do Rio de Janeiro (UERJ) & 1 \\
\hline & TOTAL & 4 \\
\hline \multicolumn{2}{|c|}{ TOTAL DE ENTREVISTADOS DA PESQUISA } & 27 \\
\hline
\end{tabular}


selecionados a partir das falas dos entrevistados (citações) e construídos quadros sintéticos oriundos da análise procedida no Atlas.ti.

A partir desses quadros, cada variável foi relacionada a uma "família de códigos" (nomenclatura utilizada pelo software), tendo sido analisados os códigos que compõem cada família e verificados os respectivos graus de fundamentação e densidade. O primeiro conceito se refere à freqüência de aplicação de um código, ou seja, ao número de citações ligadas a ele. O segundo evidencia o número de ligações de um determinado código a outros códigos, exprimindo sua complexidade.

Tendo em vista a utilização de falas dos entrevistados no decorrer da discussão se estabeleceu uma identificação dos informantes-chaves por setor institucional ao qual pertencem, do seguinte modo: (1) Setor Público: prefixo SP, numerados de 1 a 12; (2) Iniciativa Privada: prefixo IP, numerados de 1 a 5; (3) Terceiro Setor: prefixo TS, numerados de 1 a 6 e (4) Setor Acadêmico: prefixo SA, numerados de 1 a 4 . Ao serem mencionadas falas de entrevistados neste artigo, a identificação é feita como nos seguintes exemplos: entrevistado SP2, entrevistado IP5, entrevistado TS1, entrevistado SA3 e assim por diante.

\section{RESULTADOS E DISCUSSÃO}

A teoria institucional subsidiou dois tipos de análise para que se chegasse a uma avaliação sobre os estágios de institucionalização do governo eletrônico no Brasil, conforme é apresentado no Quadro 2, ao final do artigo. Procurou-se, com fundamento nessa perspectiva, visualizar a institucionalização por meio de estruturas analíticas que permitissem um melhor entendimento de como o processo vem ocorrendo no Brasil, quais sejam: (1) lógica institucional (Scott, 2001) e (2) pilares institucionais (Scott, 1994, 2001).

A primeira abordagem utilizada foi entender a lógica institucional do governo eletrônico no país, considerando o nível de análise como o de setor societário e a abrangência nacional como contexto institucional de referência. A análise foi procedida com base em cinco das oito dimensões propostas por Scott (2001) para o exame da estruturação de setores institucionais, a saber: a) centralização de recursos; b) unidade de governança; c) modo de governança público-privado; d) consenso na lógica institucional; e, e) ligações organizacionais.

Para iniciar essa investigação sobre a rationale do setor societário do governo eletrônico no Brasil, pode-se dizer, quanto à dimensão centralização de recursos, que os re- cursos estão dispersos em diversos programas governamentais, não sendo esse um problema em si. O problema, na verdade, seria exatamente a falta de coordenação da política, capaz de proteger as dotações orçamentárias do programa, por exemplo, de futuros cortes ou contingenciamentos. Esse papel, que seria do Comitê Executivo do Governo Eletrônico (CEGE), não vem sendo cumprido a contento, na opinião dos entrevistados, pois haveria a cultura, no âmbito do setor público brasileiro, de visualizar o orçamento em nichos próprios de cada órgão e não holisticamente, como seria necessário numa política de gestão pública - transversal por natureza - como a de governo eletrônico.

O entrevistado SP12 explicou essa barreira constatada no período 2000-2002, relacionando-a a problemas orçamentários com origem na falta de vinculação das diretrizes emanadas do CEGE em relação ao ritmo de liberação de recursos a projetos de e-gov designados nesse colegiado para os diversos ministérios ou entidades governamentais. Esse descompasso acarretava, ao final, níveis de execução muito diferenciados entre as organizações governamentais, o que acabava impactando o macroplanejamento inicial para ações de governo eletrônico como um todo.

A causa dessa execução orçamentária em níveis diferenciados é devida, na opinião dos entrevistados, à dispersão dos recursos de governo eletrônico no orçamento público, sem que houvesse uma coordenação centralizada capaz de "proteger" as dotações de futuros cortes objetivando "gerenciar os recursos orçamentários pensando efetivamente numa política global e não que possam ser cortados recursos ou contingenciados os recursos indiscriminadamente" (SP7). As soluções para essa "pulverização" ineficaz de recursos ligados a e-governo no orçamento já estavam na pauta de preocupações do governo federal em seu planejamento inicial das ações ainda no ano 2000, tendo sido proposto o início de "estudos visando a individualização dos recursos de tecnologia de informação e de comunicação, no Orçamento da União" (Brasil, 2000a, p. 9).

A unidade de governança examinou se as estruturas de governança são congruentes na jurisdição e consistentes no sistema de regras enunciado e imposto. A análise dos códigos da variável Estrutura Legal mostrou que o pilar regulativo tem um peso importante para nortear o modo como os atores institucionais se relacionam no setor societário do e-gov. No aspecto macro da política, a existência de um comitê estratégico, instituído em 2000 por meio de decreto presidencial - o CEGE - e que ainda mantém sua estrutura básica de funcionamento, mostra uma certa estabilidade da legislação. 
Esse quadro, que, em princípio, indicaria a existência de uma estrutura de governança num bom estágio de desenvolvimento, ao menos no pilar regulativo, deve ser confrontado com a possibilidade de os aspectos formalísticos - característicos da sociedade brasileira (Machadoda-Silva et al., 2003) - estarem predominando nas relações entre os agentes institucionais, o que demandaria uma aceitação tanto moral quanto cultural da política nos demais pilares - normativo e cognitivo - para que o setor contasse com uma efetiva unidade de governança. A simples existência do marco legal do e-gov não seria suficiente para lhe garantir a unidade de governança. Haveria, portanto, a necessidade de se aprimorar o marco legal do governo eletrônico no Brasil, que ainda parece estar se acomodando às novas relações oriundas da Sociedade da Informação.

A relação entre as autoridades públicas e privadas na estruturação do e-gov - modo de governança público-privado - foi explorada na variável Relações Institucionais, oportunidade em que a análise ressaltou que a participação do setor empresarial seria, em princípio, benéfica ao governo eletrônico tendo em vista a possibilidade da entrada de recursos financeiros privados em projetos públicos e a introdução de novas tecnologias, além de um incremento à governança decorrente do próprio relacionamento entre esses agentes institucionais.

A esses aspectos benéficos da interação foram contrapostos riscos e receios de ambos os setores para a consolidação da interação. Do lado do governo, haveria o receio de uma "perda de controle" ao serem repassadas tarefas ao setor privado: "existe um receio muito grande do governo perder o controle a partir do momento que ele está fazendo uma parceria com a iniciativa privada" (IP2). Tais receios poderiam ser minimizados, segundo o entrevistado SP4, a partir de uma mudança de perspectiva nessas relações: "não é uma relação de cliente-fornecedor: é uma relação de parceiro".

O controle sobre o setor - essência da dimensão modo de governança público-privado - se tornaria uma preocupação do Estado quando do repasse de tarefas ao setor privado, pois haveria uma predominância da visão "cliente-fornecedor" em vez de uma perspectiva de efetiva "parceria". A partir de 2003, houve a percepção de que o Estado estaria tentando aumentar o seu controle sobre o setor por meio de medidas que visaram redução de custos, a serem alcançadas com renegociações contratuais do governo federal com seus fornecedores e com uma política de incentivo à implementação de sistemas baseados em código aberto - o que gera economias ao menos a curto prazo na aquisição de licenças.
O consenso na lógica institucional, a principal das cinco dimensões de Scott (2001) para os fins de se explorar a lógica do e-gov, mostra que os atores seguem (e a elas aderem) as mesmas crenças gerais e receitas de ação ao implementar as atividades do setor societário do e-gov. Esse raciocínio decorre da análise dos códigos da variável Relações Institucionais, que mostrou alguns bons relacionamentos setor a setor - Estado-terceiro setor, por exemplo -, mas não de um modo generalizado na política, o que resulta na ausência de um plano estratégico para governo eletrônico capaz de envolver todos os agentes institucionais. Mesmo sem esse plano, há um razoável entendimento sobre as crenças gerais e receitas de ação a serem seguidas pelos distintos stakeholders na política de e-gov.

Essa avaliação positiva dos entrevistados quanto à atuação das organizações não governamentais (ONGs) na política de inclusão digital é devida a uma crença enraizada no papel dessas organizações como representantes do terceiro setor e, portanto, legitimadas a atuarem em causas sociais, de cunho assistencialista ou não, ou mesmo no sentido institucional (cognitivo), aceitando esse pressuposto como culturalmente sustentado e conceitualmente correto (Scott, 2001).

Para evitar desvios ou a prevalência de interesses privados em detrimento dos fins públicos da política de inclusão digital, os entrevistados defenderam a idéia de que a participação da iniciativa privada tenha parâmetros ditados pelo governo, nos casos em que as empresas se propuserem a atuar em projetos conjuntos com o setor público. Além disso, a indução do governo para o financiamento da política em parceria com o capital privado seria salutar até mesmo para orientar as empresas sobre o modo de implementar essa participação.

O último aspecto da estruturação do setor societário - as ligações organizacionais - aborda a extensão na qual há um número relativamente grande de conexões formais e informais entre atores organizacionais no setor. Conforme restou evidenciado no exame das variáveis Relações Institucionais e Estrutura Legal, as conexões formais são regidas pelo pilar regulador, ou seja, o marco legal do setor. Nele está definido o modo, por exemplo, de interação de atores externos com o governo na etapa de formulação da política de governo eletrônico, por meio da participação de convidados nas discussões dos comitês técnicos do CEGE.

A criação desses comitês no âmbito do CEGE foi destacada como um avanço na construção da legislação que normatiza as ações do e-gov no país: "É um espaço de negociação das políticas, porque é uma forma de fazer com 
que a política efetivamente chegue na ponta e se enraíze, que aquilo que vira norma efetivamente seja implementado porque foi amplamente discutido no interior do governo" (SP10). Entretanto, a instituição dos comitês por meio de um decreto refletiu tão-somente uma medida de caráter coercitivo (regulador), mas que não necessariamente tem condições de se institucionalizar apenas com base na existência da norma: "na verdade, não só precisaria de uma norma mais forte que um simples decreto, como também precisaria (...) para viabilizar isso politicamente, de uma articulação muito maior" (SP2).

As ligações informais predominam, por exemplo, na política de inclusão digital, pois mesmo não havendo uma norma legal que discrimine o modo de interação com o terceiro setor, nota-se que esse ator institucional influencia a política, fruto de um bom relacionamento com o setor público e mesmo com os demais setores. O entrevistado TS3 evidencia a importância do poder público no fomento a esses espaços de discussão: "o governo tem um poder de articulação muito grande, de mobilização da sociedade, sociedade civil, grupos econômicos".

O ferramental analítico baseado nos três pilares institucionais propostos por Scott $(1994,2001)$ constituiu o segundo enfoque para se avaliar o processo de institucionalização do e-gov no Brasil. Quanto ao pilar regulador, depreende-se que é o de maior peso para a sustentação da política. O marco legal do governo eletrônico mostra-se razoavelmente bem estruturado, com as ressalvas feitas anteriormente ao se explorar a dimensão unidade de governança, utilizada para explicar a estruturação e a lógica institucional do setor. A investigação desse pilar centrou suas atenções em torno da capacidade de enforcement do governo federal, ou seja, sua habilidade em moldar a interação entre os atores na forma de padrões aceitáveis e reduzir a incerteza.

Foi apontado o risco de o formalismo estar impactando esse pilar, em prejuízo do cumprimento das normas que regem o setor. A simples existência do marco legal do e-gov não seria suficiente, portanto, para garantir nem sua governança nem um caminho estável rumo a estágios superiores de institucionalização. Essa situação teria ocorrido no período 2000-2002, de acordo com o entrevistado SP3.

O pilar normativo abordou os aspectos representativos, constitutivos e normativos da política de governo eletrônico, atendo-se aos valores e normas vigentes. O primeiro aspecto - representativo - está relacionado à lógica institucional do setor, tendo sido investigado anteriormente por meio das dimensões propostas por Scott (2001, p. 202) para o exame da estruturação de setores institucionais, es- pecialmente quanto à dimensão consenso na lógica institucional. Os aspectos constitutivos referem-se à natureza dos atores e à sua capacidade de ação, além de considerar sua própria construção social, ou seja, os atores não atuariam "por acaso". Essa dimensão do pilar normativo foi tratada na análise dos códigos pertencentes à variável Formulação/ Integração de Políticas, no qual ficou evidenciada a necessidade de se abrirem discussões sobre a política de governo eletrônico de uma forma mais ampla e efetiva aos agentes institucionais externos ao setor público.

Percebeu-se, ainda, que, para a política de governo eletrônico, a iniciativa privada teria um papel importante na introdução de capital privado em projetos de e-gov, enquanto a academia estaria dando contribuições importantes na pesquisa voltada a temas tecnológicos. Já o terceiro setor teria pouca capacidade de contribuição à política de inclusão digital caso implementasse projetos de forma isolada do setor público, que é o agente institucional capaz de gerar escala das ações: "o governo tem condições de dar escala" (TS3).

O terceiro pilar institucional, o cultural-cognitivo, tratou dos sistemas de significação e padrões relacionados de comportamento dos atores institucionais, ou seja, dos significados que os constituintes do processo dão às ações, estando relacionados à aceitação de pressupostos. Esse pilar considera os padrões de comportamento dos agentes na interpretação desses significados. Um primeiro exemplo de como a política de e-gov pode ser influenciada por esse pilar é o papel do formalismo na aceitação das leis e normas que incidem sobre o setor. Mais eficaz que os mecanismos de sanção, especialmente na sociedade brasileira, é a aceitação cultural dos constituintes das relações regidas por tais normas, para que as situações previstas na legislação encontrem correspondência na realidade social.

Um exemplo de pressuposto dominante na política de inclusão digital - embora não tenha sido objeto de consenso entre os entrevistados - é que o terceiro setor estaria legitimado a atuar em causas sociais, na implementação do que é conhecido como "modelo filantrópico" de inclusão digital (Toledo, 2004), crença que estaria culturalmente sustentada no Brasil. Essa legitimidade não foi reconhecida plenamente pelos entrevistados pelo fato de existirem ONGs com interesses escusos, que poderiam não se encaixar nessa crença geral de benevolência que seria, em princípio, intrínseca a esse tipo de organização. De qualquer modo, essa percepção não alterou a avaliação sobre a boa integração existente entre Estado e terceiro setor, especialmente na fase de planejamento da política de inclusão digital. 


\section{CONCLUSÕES}

Quanto à institucionalização da política de e-gov no Brasil, as principais conclusões obtidas após a análise de sua lógica institucional (Scott, 2001) e de suas características ante os pilares institucionais (Scott, 1994, 2001) apontam no sentido de que esta deva ter continuidade ao longo do tempo para que se institucionalize, mesmo com as mudanças de governo, que sua estrutura legal seja constantemente aprimorada e que o tema passe a ser discutido de uma forma mais ampla entre os atores institucionais.

O principal empecilho ao progresso da institucionalização do e-gov seria a falta de uma instância de coordenação centralizada sobre o orçamento público no programa de governo eletrônico, capaz de negociar com a área econômica do Poder Executivo os recursos a serem nele empregados.

A perspectiva atual que se tem sobre o estágio de institucionalização do governo eletrônico no Brasil é apresentada no Quadro 2, formulada com base na análise procedida em relação às três variáveis do estudo e fundamentada nos estágios de institucionalização propostos por Tolbert e Zucker (1997, p. 185), a saber: I: estágio pré-institucional; II: estágio semi-institucional; III: estágio de total institucionalização.

O estágio semi-institucional da maioria dos aspectos relacionados ao e-gov - ou seja, no estágio de objetificação (Tolbert e Zucker, 1997) - é um resultado esperado, tendo em vista o espaço de tempo relativamente curto desde que a política foi implantada no Brasil (iniciada em 2000 com a implantação do Comitê Executivo do Governo Eletrônico - CEGE).

Depreende-se que, à exceção do relacionamento entre o setor público e o terceiro setor na política de inclusão digital, ainda há que se promover melhorias nos demais aspectos apresentados no Quadro 2 - especialmente naqueles relacionados à formulação e integração da política, bem como ao seu marco legal - para que estes progridam em seus respectivos estágios de institucionalização, rumo a processos sedimentados (Tolbert e Zucker, 1997).

Preferiu-se avaliar os estágios em relação a cada uma das variáveis da pesquisa em vez de se propor o reconhecimento dicotômico do governo eletrônico como algo institucionalizado ou não institucionalizado, porque o próprio processo de institucionalização não se constitui em algo dicotômico do tipo sim ou não.

Quanto aos reflexos da política de e-gov na inclusão digital (ID) - não obstante o bom relacionamento entre o Estado e o terceiro setor -, ela não pode ser caracterizada verdadeiramente, até o momento, como uma política pública, razão pela qual se optou pelo seu enquadramento no estágio pré-institucional (veja "Políticas de inclusão digital" no Quadro 2).

De qualquer modo, ao menos em termos do discurso do Poder Executivo e levando-se em consideração a existência de um comitê específico para formular as ações de inclusão digital no âmbito do Comitê Executivo do Governo Eletrônico, há o interesse do governo federal em

Quadro 2 - Grau de institucionalização do governo eletrônico no Brasil

\begin{tabular}{|c|c|c|c|c|c|}
\hline \multirow{2}{*}{\multicolumn{2}{|c|}{ VARIÁVEIS }} & \multirow{2}{*}{ PRINCIPAIS ASPECTOS } & \multicolumn{3}{|c|}{ ESTÁGIOS } \\
\hline & & & I & II & III \\
\hline \multirow{15}{*}{ 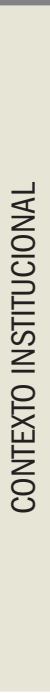 } & \multirow{5}{*}{ Formulação/Integração de Políticas } & Programa Governo Eletrônico & & $\checkmark$ & \\
\hline & & Políticas de inclusão digital & $\checkmark$ & & \\
\hline & & Programa Sociedade da Informação & $\checkmark$ & & \\
\hline & & Orçamento & & $\checkmark$ & \\
\hline & & Plano estratégico & $\checkmark$ & & \\
\hline & \multirow{5}{*}{ Relações Institucionais } & Relação Estado-iniciativa privada & & $\checkmark$ & \\
\hline & & Relação Estado-setor acadêmico & & $\checkmark$ & \\
\hline & & Relação Estado-terceiro setor & & & $\checkmark$ \\
\hline & & Relação iniciativa privada-terceiro setor & & $\checkmark$ & \\
\hline & & Relacionamento entre atores & & $\checkmark$ & \\
\hline & \multirow{5}{*}{ Estrutura Legal } & Legislação & & $\checkmark$ & \\
\hline & & Legislação - software livre & $\checkmark$ & & \\
\hline & & Legislação - certificação digital & & $\checkmark$ & \\
\hline & & Legislação - compras eletrônicas & $\checkmark$ & & \\
\hline & & Legislação - inclusão digital & $\checkmark$ & & \\
\hline
\end{tabular}


integrar a modernização administrativa que o e-gov pode proporcionar a políticas de inclusão social (Dias, 2003), o que deve acarretar, nos próximos anos, uma valorização da ID como uma das principais estratégias do governo eletrônico no Brasil.

Os principais limites do estudo referem-se, especialmente, a dois aspectos. O primeiro deles devido ao pouco tempo de atuação do CEGE a partir de 2003 para que se pudesse avaliar sua atuação em relação ao período 20002002. O segundo refere-se ao fato de a pesquisa ter englobado o primeiro ano de gestão do governo empossado em 2003, o que significou novos direcionamentos para a política de e-gov a partir de então, com reflexos nas conclusões do estudo.

Para estudos futuros, sugere-se que a estrutura de análise utilizada nesta pesquisa - baseada na teoria institucional - seja empregada para investigar casos de e-gov estaduais ou mesmo fazer estudos sobre a relação institucional do programa de governo eletrônico federal com aqueles implementados pelos estados e municípios.

\section{REFERÊNCIAS}

BERGER, P.; LUCKMANN, T. The Social Construction of Reality: A Treatise in the Sociology of Knowledge. London: Allen Lane, 1966.

BRASIL. Proposta de política de governo eletrônico para o Poder Executivo federal. Grupo de Trabalho "Novas Formas Eletrônicas de Interação". Brasília: Ministério do Planejamento, Orçamento e Gestão, 2000a.

BRASIL. Ministério da Ciência e Tecnologia (MCT). Sociedade da Informação no Brasil - Livro Verde. Brasília: MCT, 2000b.

BRASIL. Dois anos de governo eletrônico - Balanço Preliminar. Brasília: Casa Civil da Presidência da República, Ministério do Planejamento, Orçamento e Gestão, Secretaria Executiva do Comitê Executivo do Governo Eletrônico, 2002.

CARVALHO, C. A.; VIEIRA, M. M. F. Contribuições da Perspectiva Institucional para Análise das Organizações: Possibilidades Teóricas, Empíricas e de Aplicação. In: CARVALHO, C. A.; VIEIRA, M. M. F. (Orgs.). Organizações, cultura e desenvolvimento local: a agenda de pesquisa do Observatório da Realidade Organizacional. Recife: Editora Universitária UFPE, 2003. p. 23-40.

DIAS, L. R. (Coord.). Inclusão digital: com a palavra, a sociedade. São Paulo: Plano de Negócios, 2003.

DINIZ, E. Governo digital. Montevidéu: Associação Latino-Americana de Integração (Aladi), 2002.
FERGUSON, M. Estratégias de governo eletrônico: o cenário internacional em desenvolvimento. In: EISENBERG, J.; CEPIK, M. (Orgs.). Internet $e$ política: teoria e prática da democracia eletrônica. Belo Horizonte: Editora UFMG, 2002. p. 103-140.

FOUNTAIN, J. E. Building the Virtual State: Information Technology and Institutional Change. Washington: Brookings Institution Press, 2001 .

KAKABADSE, A.; KAKABADSE, N. K.; KOUZMIN, A. Reinventing the democratic governance project through information technology? A growing agenda for debate. Public Administration Review, v. 63, n. 1, p. 4460,2003

MACHADO-DA-SILVA, C. L.; GONÇALVES, S. A. Nota técnica: a teoria institucional. In: CLEGG, S.; HARDY, C.; NORD, W. R. (Orgs.). Handbook de estudos organizacionais. São Paulo: Atlas, 1998. p. 220-226.

MACHADO-DA-SILVA, C. L.; FONSECA, V. S.; FERNANDES, B. H Cognição e institucionalização na dinâmica da mudança em organizações. In: RODRIGUES, S. B.; CUNHA, M. P. (Orgs.). Estudos organizacionais: novas perspectivas na administração de empresas. São Paulo: Iglu, 2000 p. $123-150$

MACHADO-DA-SILVA, C. L.; GUARIDO FILHO, E. R.; NASCIMENTO, M. R.; OLIVEIRA, P. T. Institucionalização da mudança na sociedade brasileira: o papel do formalismo. In: VIEIRA, M. M. F; CARVALHO, C. A. (Orgs.). Organizações, instituições e poder no Brasil. Rio de Janeiro: Editora FGV, 2003. p. 179-202.

MEYER, J. W.; BOLI, J.; THOMAS, G. M. Ontology and rationalization in the Western cultural account. In: SCOTT, W. R.; MEYER, J. (Orgs.) Institutional Environments and Organizations: Structural Complexity and Individualism. Thousand Oaks, CA: Sage, 1994. p. 9-27.

NAÇÕES UNIDAS. Benchmarking E-Government: a global perspective. New York: United Nations, American Society for Public Administration, 2002.

OKOT-UMA, R. Electronic Governance: Re-inventing Good Governance. London: Commonwealth Secretariat London, 2001.

POWELL, W. W.; DIMAGGIO, P. J. The New Institutionalism in Organizational Analysis. Chicago: The University of Chicago Press, 1991.

RICHARDSON, R. J. et al. Pesquisa social: métodos e técnicas. São Paulo: Atlas, 1985.

RUEDIGER, M. A. Governo eletrônico ou governança eletrônica - conceitos alternativos no uso das tecnologias de informação para o provimento de acesso cívico aos mecanismos de governo e da reforma do Estado. In: Concurso de Ensayos y Monografías del CLAD sobre Reforma del Estado y Modernización de la Administración Pública, 16., 2002, Caracas. Anais eletrônicos. Caracas: CLAD, 2002. 
RUEDIGER, M. A. Oferta de serviços pela Internet e inclusão digital. In: Assembléia Anual do Cladea, 38., 2003, Lima. Anais eletrônicos. Lima: Conselho Latino-Americano de Escolas de Administração (Cladea), 2003.

SCOTT, W. R. Institutions and organizations: toward a theoretical synthesis. In: SCOTT, W. R.; MEYER, J. (Orgs.). Institutional Environments and Organizations: Structural Complexity and Individualism. Thousand Oaks, CA: Sage, 1994. p. 55-80.

SCOTT, W. R. Organizations: Rational, Natural, and Open Systems. Upper Saddle River, NJ: Prentice Hall, 1998.

SCOTT, W. R. Institutions and Organizations. Thousand Oaks, CA: Sage, 2001.

SCOTT, W. R.; MEYER, J. W. The organization of societal sectors: propositions and early evidence. In: POWELL, W. W.; DIMAGGIO, P. J. (Eds.) The New Institutionalism in Organizational Analysis. Chicago: The University of Chicago Press, 1991. p. 108-140
SCOTT, W. R. (Org.). Institutional Environments and Organizations: Structural Complexity and Individualism. Thousand Oaks, CA: Sage, 1994

SILVEIRA, S. A. Exclusão digital - A miséria na era da informação. São Paulo: Fundação Perseu Abramo, 2001.

TOLBERT, P. S.; ZUCKER, L. G. The institutionalization of institutional theory. In: CLEGG, S.; HARDY, C.; NORD, W. R. (Orgs.). Handbook of Organizational Studies. London: Sage, 1997. p. 175-190.

TOLEDO, P. F. Inclusão digital - Uma proposta empreendedorista. In: CHAHIN, A. et al. E-gov.br - A próxima revolução brasileira. São Paulo: Prentice Hall, 2004. p. 269-277.

VALA, J. A Análise de conteúdo. In: SILVA, A. S.; PINTO, J. M. (Orgs.) Metodologia das ciências sociais. 8. ed. Porto: Afrontamento, 1986. p. 101-128.

Artigo recebido em 20.01.2005. Aprovado em 29.09.2005.

\section{Paulo Henrique Ramos Medeiros}

Analista de Controle Externo do Tribunal de Contas da União. Mestre em Administração pela UnB.

Interesses de pesquisa nas áreas de governo eletrônico, governança, governança eletrônica, inclusão digital, reforma administrativa e teoria institucional.

E-mail: paulohr@tcu.gov.br

Endereço: SQN 212, Bloco D, apto. 302, Asa Norte, Brasília - DF, 70864-040.

Tomás de Aquino Guimarães

Professor da UnB. Doutor em Sociologia pela USP.

Interesses de pesquisa nas áreas de competência e aprendizagem em organizações, inovações gerenciais e teoria institucional

E-mail: tomas@unb.br

Endereço: SQN 116, Bloco I, apto. 305, Asa Norte, Brasília - DF, 70773-090. 